\title{
Correction to: Gilteritinib: a novel FLT3 inhibitor for acute myeloid leukemia
}

Juanjuan Zhao ${ }^{1}$, Yongping Song ${ }^{1 *}$ and Delong Liu ${ }^{1,2^{*}}$

Correction to: Biomark Res (2019) 7:19

https://doi.org/10.1186/s40364-019-0170-2

The original article [1] contains an error in the legend of Fig. 1 whereby it is incorrectly stated that MEC stands for 'mitoxantrone, etoposide, cyclophosphamide'.

It should instead be stated that MEC stands for 'mitoxantrone, etoposide, cytarabine'.

\section{Author details}

${ }^{1}$ Department of Oncology, The first Affiliated Hospital of Zhengzhou

University, Zhengzhou, China. ${ }^{2}$ Division of Hematology and Oncology, New

York Medical College, Valhalla, USA.

Published online: 17 October 2019

\section{Reference}

1. Zhao J, Song Y, Liu D. Gilteritinib: a novel FLT3 inhibitor for acute myeloid

leukemia. Biomarker Research. 2019;7:19. https://doi.org/10.1186/s40364-019-0170-2.

\footnotetext{
*Correspondence: songyongping@163.com; DELONG_LIU@NYMC.EDU

${ }^{1}$ Department of Oncology, The first Affiliated Hospital of Zhengzhou

University, Zhengzhou, China

Full list of author information is available at the end of the article
} 